This is the accepted manuscript of an article published in Interchange, Vol. 50, No. 2, pp. 187203, April 2019. The final publication is available here.

\title{
Teaching Philosophy in Central Asia: Effects on Moral and Political Education
}

\section{Elena Popa}

\begin{abstract}
This paper investigates how an introductory philosophy course influences the moral and political development of undergraduate students at a Liberal Arts university in Central Asia. Within a context of rapid changes characteristic of transitional societies, reflected in the organization of higher education, philosophy provides students with the means to reason about moral and political values in a way that overcomes the old ideological tenets as well as contemporary reluctance to theoretical inquiry. Studying philosophy provides a remedy for deficiencies in both secondary and higher education, by improving general reading and reasoning skills that enable the development of moral thinking. Furthermore, familiarity with major works of moral and political philosophy can help students comprehend the patterns of social change, as well as surmount the issue of unsatisfactory theoretical foundations for social science.
\end{abstract}

\section{Introduction}

Instilling the ability to reason about moral values plays a central role among the aims of education. This has been acknowledged within the philosophy of education (Siegel 2009), and it is reflected in the Liberal Arts tradition in the United States (McNeel 1994). This paper investigates how these broad philosophical considerations alongside cognitive aspects of moral development function in Central Asia, a region where Liberal Arts universities are part of a wider pattern of emerging changes in higher education, including an international scope and increasing numbers of undergraduate students. I focus on how philosophy, as one of the fundamental subjects of the Liberal Arts associated with moral education, can contribute to the students' moral development in a context of rapid change, with little previous exposure to humanities education.

There are two aspects to consider in addressing this question. Firstly, there are patterns in moral development and higher-level moral reasoning holding across different cultures and education systems. In this sense, I will employ contributions by Kohlberg (1975) to emphasize the importance of autonomous moral reasoning, and by Nucci (2005) to capture the pluralistic 
dimension of moral education. Secondly, there are regional challenges characteristic of an emerging society: material limitations, insufficient expertise, insufficient data, and overall unreliability of the university structure. Owing to two particular aspects of transition - the search for meaning in the aftermath of the collapse of Soviet ideology, and the recent neglect of theoretical subjects - I argue that an introductory course in philosophy helps students reflect on moral and political values from a perspective that can address these challenges. Philosophy provides students with the tools to assess the rapid social changes, as well as gain a sense of the importance of moral and political questions.

My argument builds upon the experience of teaching an Introduction to Philosophy course for four semesters at an English-speaking university in Bishkek, Kyrgyzstan. In addition to an analysis considering broader principles of moral education, I employ student answers to a post-course questionnaire, classroom observations, and student feedback collected throughout several semesters. I argue that a generalist approach to philosophical topics, in addition to contributing to general reasoning skills necessary for moral reasoning, fosters moral and political values through exposing students to viewpoints and arguments different from their own. The contributions to the students' moral development are both direct by exposure to moral views, arguments, and dilemmas, and indirect through fostering reasoning skills and sketching out broader perspectives. These developments in moral reasoning, supported by cognitive approaches to moral education, can further help address issues stemming from the social context in Central Asia and encourage pluralism about social values characteristic of Liberal Arts education.

\section{Background: Moral education}

In order to trace particular features of moral thought, and patterns of development in students' reasoning I employ perspectives from two types of cognitive approaches: a hierarchical model leading up to moral autonomy (Kohlberg 1975), and a domain approach relying on a pluralistic framework (Nucci 2005). This will provide a perspective that distinguishes between general issues in moral development and problems specific to Central Asia, as well as enable potential uses of the present analysis for investigations of moral education in comparable contexts. Kohlberg's hierarchical model comprises a distinction between several stages of development (as in Piaget's work), a Kantian understanding of moral autonomy, and an overall view on education drawing from Dewey. ${ }^{1}$ The stages singled out by Kohlberg are pre-conventional, conventional, and post-conventional (or autonomous). The autonomous stage is analogous to the Kantian

1 See Piaget (1932), Kant (trans. 2002), Dewey (1964). 
categorical imperative, thus in Kohlberg's view moral development progresses towards a universal perspective. It is precisely universalism which has been subject to criticism, and contrasted with a pluralistic perspective. Nucci emphasizes that conventions and universal rules are two independent frameworks, rather than hierarchical stages, and are always present throughout the process of moral development. Despite the philosophical differences between the two views, as I point out below, the curriculum recommendations as well the focus on the process rather than the product of reasoning are present in both views.

Regarding Kohlberg's work, the transition from the conventional to the autonomous level (or at least to its understanding), will be relevant for my argument. At the conventional level, moral norms would be justified by peer approval, or obedience to law and order would be practiced for their own sake (Kohlberg 1975, p. 671). In this sense, the following classroom experience is illustrative: during a discussion on civil rights, some students would support law enforcement violence towards peaceful protesters for the sake of 'order'. At the autonomous level moral rules are first obeyed for the sake of social cohesion, or, at the highest stage, for their value as principles. In this sense moral norms would be justified by 'ethical principles appealing to logical comprehensiveness, universality, and consistency'; 'universal principles of justice, of the reciprocity and equality of human rights and of respect of the dignity of human beings as individual persons’ (p. 671). The analogy with logic here deserves further emphasis. Kohlberg notes that logical reasoning is necessary for reaching autonomous moral reasoning: 'since moral reasoning clearly is reasoning, advanced moral reasoning depends upon advanced logical reasoning' (p. 671). Nevertheless, moral reasoning poses a more significant challenge for education than logical reasoning: 'over $50 \%$ of late adolescents and adults are capable of full formal reasoning, but only $10 \%$ of these adults (all formal operational) display principled (Stages 5 and 6) moral reasoning' (p. 671). This point is especially relevant for framing expectations concerning moral development in the context of higher education. Most students are not expected to reach moral autonomy, but rather to build an understanding of the higher levels and move closer to a more advanced stage. A final point from Kohlberg's work relevant for my purposes here are the suggested steps in stimulating students to reach higher stages of moral understanding: (a) seeking a change in reasoning rather than belief; (b) aiming for individual improvement, rather than convergence, since not all students are at the same level; (c) not emphasizing the teachers' opinion; (d) stressing that some judgments are more adequate than others (p. 674).

Regarding Nucci's domain approach, the departure point from Kohlberg's views should be emphasized: 'in contrast with the Kohlbergian view of development, in which morality is 
gradually differentiated from and eventually displaces convention as a basis for making moral judgments, domain theory maintains that conceptions of morality and convention coexist as separate conceptual frameworks throughout the developmental process’ (Nucci 2005, p. 661). Nucci further adds to Kohlberg's take on the goals of moral education, which 'are extended to the more complex task of increasing the ability and tendencies of students to evaluate and coordinate the moral and nonmoral elements of multifaceted social issues' (p. 662). This aspect, I argue, is highly relevant in the current context of Central Asia, where students need to recognize and assess moral issues specific to emerging societies. While according to Nucci's approach the conventional and autonomous stages are not necessarily hierarchical, and can be viewed as different ways of viewing morality, there are points of convergence with Kohlberg's approach. Notably, the views on students' construction of moral views are similar: 'moral development requires students' construction of their own understandings of fairness and not simply the appropriation of adult norms and values' (p. 665). Thus, common recommendations for developing moral reasoning can hold across the two approaches.

This paper broadly endorses a pluralist view, which enables more diversity in moral reasoning, while also emphasizing the convergence on means of stimulating moral thought. For instance, concerning the curriculum, Nucci holds that 'a developmental approach (...) recognizes the unique role of curricular sources of moral content for the broader goals of moral education. Challenging students' broader conceptions of the morality of social systems, particularly the cultural assumptions and values of the system they inherit, requires going beyond direct personal experience' (p. 671). In this sense, recognizing a plurality of moral views is merged with a universal perspective enabling students to step beyond their own views and experiences. Thus, Nucci's emphasis on pluralism can be integrated with Kohlberg's case for autonomous moral reasoning.

\section{Context and challenges in Central Asia}

While the studies above take the cognitive bases of moral education to be uniform across individuals, their discussions of the curriculum, educational background, and wider social context focus on the United States. Other investigations of moral education have concentrated on different areas (see Jarrar 2013 for Jordan), but the context of Central Asia rests largely unexplored against this theoretical framework. This section focuses on challenges faced by higher education in Kyrgyzstan particularly, extending the analysis to other states in the region. The aim is to investigate how the recommendations of the cognitive approach to moral and political education discussed can be implemented in the Central Asian context. 
I consider two sets of challenges. Firstly, concerning the preparation students receive before enrolling at a university, there is little data on secondary school students' overall performance, and even less on moral education. Where there is information, the statistics are worrisome. Secondly, there are specific issues with adopting a theoretical framework for moral and political education after the demise of the Soviet ideology, concerning higher education particularly. I explore these within the context of Kyrgyzstan, while pointing to similarities with other Central Asian states.

A 2006 study by DeYoung emphasizes the difficulties of assessing the state of education in Kyrgyzstan:

Another "from the ground" issue witnessed during this fieldwork was the real absence of Ministry experts or expertise related to such areas as school management, tests and measurement, and program evaluation: effects of classroom size on learner outcomes; norm-based versus criterion-based achievement tests to focus the curriculum upon; and strategies and issues in the construction of a standardized national achievement test (...) there is virtually no one to even have these conversations with’ (DeYoung 2006, p. 222).

DeYoung notes that little had changed in a more recent article (2013): the expertise is insufficient, as the few specialists prefer the private sector. A study by Rahmetov (2009) points out that the results obtained by students from Kyrgyzstan at PISA tests ranked the lowest out of 57 countries. Pointed, there are no results of PISA recorded since. ${ }^{2}$ While this raises worries concerning reading abilities and general reasoning skills, which, as mentioned by Kohlberg are required for the higher stages of moral reasoning, a further issue is the theoretical frame for moral education. As specified by DeYoung, when Kyrgyzstan was part of the Soviet Union 'compulsory secondary education, as well as the various forms of higher education, also had a moral and a philosophical emphasis: vospitanie, or social upbringing' (2013, p. 160). After independence, it is still not clear what the grounds for moral education are: 'even without a cohesive national ideology to focus upon, schools and universities are still required to provide a guided, morally appropriate socialization process for students (...) about a third of Kyrgyzstanis are not ethnically Kyrgyz, so the unwritten history of the Kyrgyz people cannot suffice as the moral centre' (p. 162). As my study includes students from the region pursuing undergraduate degrees in Kyrgyzstan, similar challenges should be noted. For instance, in Tajikistan postindependence secondary education has faced comparable issues after the fall of the Soviet

2 See Shamatov (2014, pp. 44-45) for an explanation referring to political reasons. 
Union: 'contradictory realities of (...) teaching are not simply an issue of teacher mentality or weakness. Their dilemmas and tensions reveal the fundamental contradictions of educational and societal reform in the Post-Soviet emerging societies' (Nyozov 2004, p. 58). Another example is Afghanistan, from where a significant number of students pursue higher education in Kyrgyzstan. The educational challenges in the post-war society there are comparable to issues in other Central Asian states: lack of funding, insufficient qualified teachers, and poor recordkeeping (Buckland 2006, Semedy 2011). I hold that these issues can be approached both from the perspective of universal moral principles emphasized by Kohlberg, and the pluralistic framework supported by Nucci. Introductory courses in philosophy, and in particular courses on value theory or ethics can provide students knowledge of moral systems transcending the bygone ideological tenets, that are general enough to accommodate the ethnic diversity of the newly founded states.

The issue of theoretical grounds particularly affects higher education, as there appears to be no basis for social science education. Reeves (2006) illustrates this by reference to the state of sociology in the post-Soviet setting:

Constrained in both content and analysis by the particular interpretative paradigm of Marxism-Leninism, these disciplines, and their practitioners, now faced a huge dilemma in determining exactly how they should position themselves in relation to former theoretical orthodoxies (...) The current privileging of quantitative over qualitative methods, and measurement techniques over theory in the sociology department's curriculum, suggests that the passion for "objective knowledge”, purged of speculative "ideology” runs deep in contemporary Kyrgyzstani social science’ (pp. 371-372).

My perspective here does not endorse the dichotomy between 'objective knowledge' and 'ideology', as objectivity also requires a philosophical stance, which is absent in the theoretical void singled out above. Nevertheless, there are serious meta-theoretical issues to stress. The demise of Marxism-Leninism, appears to have brought about the dismissal of any philosophical or theoretical dimensions to social science. As pointed out by Merrill (2011), during the time of the Soviet Union, the Marxist-Leninist orthodoxy was used to integrate the social science curriculum in higher education institutions, while also dis-integrating it from social research outside the Soviet Union (pp. 18-19). With the fall of Soviet ideology, the absence previous ties to other social research programs, and the rise of market forces as the driving factor in higher education (see Reeves 2005), the absence of theoretical foundations for social science remains a 
serious yet neglected issue. Currently, this is visible in university classrooms, as will become apparent below, and it can also be noted when examining research practices in the area, particularly the focus on descriptive aspects, when, as the situation of education shows, a normative dimension is required.

A worrying consequence of the above affects precisely moral education, and, more generally, values. Even in success stories, a big question concerns whether there is more to teaching critical thinking and the values of Liberal Arts than students employing a certain vocabulary. Though there are several international universities in Bishkek, the focus here concerns English-language universities following the Liberal Arts model. In this sense, Reeves (2006) provides an illustrative remark concerning an English-language university, namely that it 'has proven remarkably successful in producing graduates fluent, not just in English, but in the conceptual language of late capitalism and liberal individualism who have entered western graduate schools, international organizations, and well-paid jobs in businesses with relative ease' (p. 379). One issue here, again, concerns the unavailability of statistics concerning both the skills university graduates gain, and their professional trajectories. More importantly, there are many open questions about the reasoning process beyond verbal abilities: as stated by Kohlberg, moral reasoning does not entail moral action; likewise, the ability to use moral concepts does not entail the ability to reason morally.

In addition to the social background sketched above, further challenges about the system of higher education and in particular the organization of the university where the study was conducted should be noted. Firstly, concerning planning, one persistent issue has been the high faculty and staff turnover. For instance, in a department comprising around 20 faculty, only $40 \%$ had been at the university for three years or longer. The changes to the curriculum and organization varied with the coming and going department heads (for example, there have been instances when students had been announced that there would be no readers for a course just before the start of the new term, or made to enrol in a course exceeding the cap by $25 \%$ so that no sections of the course would be taught during the subsequent semester). In addition to lowering the instructional quality, such issues generate an atmosphere of insecurity and distrust. Secondly, the questionable interpretation of the Liberal Arts - with focus on poorly planned electives and disregard of foundational courses - has a systematic negative impact on scholarship and academic quality. For instance, one consistent tendency has been to remove required courses, and present them as part of the first year composition course, whose objectives do not fully overlap with the respective courses or academic fields. While in theory this offers students more choice, the lack of planning of electives results in numerous cancelled courses with no 
guarantee that students would take any courses on subjects such as philosophy, history, or literature when seemingly 'easy' courses of questionable academic quality are available, in what DeYoung (2013) describes as a 'course bazaar'. Furthermore, given the aversion to theory characteristic to post-independence social science pointed out by Reeves, the effects of this policy are potentially ruinous from a Liberal Arts perspective, reinforcing the pre-existing tendency in the majority of students to dismiss academic material with no immediate usefulness, or scholarly approaches overall. Problems of this kind mirror the instability of Post-Soviet societies, though their source rests in how the university is managed 'from the ground'. From a broader perspective, the volatility of the curriculum and overall organization of the university is indicative of an inadequate institutional structure.

Before moving on to the discussion of the course one caveat is necessary with regard to content. One may raise the issue that it is not only the lack of previous exposure to scholarship and academic skills on the students' part that constitute the main challenge, but their unfamiliarity with the Western philosophical tradition. Thus, the question is whether approaching philosophy through different readings would bypass issues regarding text understanding. In providing a negative answer to this worry, I consider possible alternatives. Firstly, students from the post-Soviet Central Asian states tend to associate philosophy with Soviet dialectical materialism, at least at the level of vocabulary. ${ }^{3}$ In this sense it is illustrative to note repeated instances of students’ classifying Plato’s metaphysics as ‘idealism’ and subsequent puzzlement when receiving the explanation that Plato's view with regard to the world of ideas is classified as 'realism'. This reflects that in the absence of adequate support from schools, students relied on obsolete material, with no principles, or arguments, or broader philosophical viewpoints they could articulate. Thus, although students may have been acquainted with philosophy from old text books, they had no familiarity with philosophical writing, and definitely not with primary sources. Secondly, it may be claimed that philosophical content closer to Central Asian culture may be approached with more ease. While this idea may be implemented in the future, when students would have access to translations and commentaries by reputable scholars, this is hardly feasible in the current setting. While there have been attempts at reclaiming notable historical figures, and connecting them to the present-day Central Asian states, these endeavours are a long way from providing materials or expertise to introduce students to basic concepts of philosophy, political thought, or history. ${ }^{4}$ In summary, until more

3 See Graham (1972) for a study of dialectical materialism in the Soviet Union.

4 The example of Yusuf Balasaguni, the $11^{\text {th }}$ century thinker from the Karakhanid khanate, is illustrative in this sense: the $1000^{\text {th }}$ anniversary of the philosopher's birth brought about an initiative to translate his work in Kyrgyz 
stable foundations to philosophy are given a place in pre-university education in Kyrgyzstan and the region overall, rather than assuming a certain background and familiarity with texts at undergraduate level, it is more fruitful to focus on patterns of reasoning, which can be taught on the basis of any philosophical tradition as long as resources are available. The focus on reasoning will further enable students to explore philosophical texts of their interest.

Given these challenges, I argue that an introductory philosophy course at undergraduate level aids the students' moral development both directly, in mapping out moral views, arguments, and dilemmas, and indirectly, in improving reasoning skills, and presenting them with a wider viewpoint. Enlarging students' perspective is particularly important, especially given the unlikely prospects of a cohesive view based on nationality in multi-ethnic societies. Thus, the universal scope of philosophy may assist in providing a general framework within institutions accommodating students from backgrounds of varying degrees of similarity. It is important to note that philosophy would not merely fill the void with yet another ideology, but provide a more general, pluralistic view, with space for disagreement, as specified in Nucci's study. Also, the universality of philosophical questions can help recognize and take a stance on the unstable social and educational system, and encourage reflection on overarching moral principles.

\section{Moral and Political Education through Introduction to Philosophy}

This study is based on teaching 'Introduction to Philosophy' to undergraduates from different departments at a Liberal Arts institution in Bishkek, Kyrgyzstan. While the course was intended as a standard introduction to the discipline, as explained in the section above, the circumstances were by no means standard. For the majority of the students this was the first time they were exposed to the works of the classic authors in philosophy and were engaged in extensive close reading practices and argumentation. There were no prerequisites, although most students took the course during their sophomore year, following a first year writing course which included a few philosophical texts. The course objectives emphasized familiarization with philosophical concepts and arguments, reading and reasoning skills, and the use of the philosophical toolkit for the disciplines in which the students specialized (see Appendix A). As no specific ethical or political education goals were set, the expected benefits to moral and political education are

(revealing that no such translations were considered in the past), but mainly served present-day political purposes, and the target audience included, among others, the participants to the opening of the 2016 World Nomad Games (Khamidov 2016). The situation is further complicated by bringing into question how representative Yusuf Balasaguni is for contemporary Central Asian identity beyond geographical placement and having written in a language from the Turkic group. 
assumed to be indirect. Nevertheless, certain texts in the syllabus discussed ethical and/or political issues: Plato’s Republic, Aristotle’s Nicomachean Ethics, Nietzsche’s 'Morality as AntiNature' from The Twilight of Idols (see the reading list in Appendix A). As it would take more than a course to address the knowledge gaps left by deficient secondary education, the assumption was that students had very little to no background in philosophy, thus the lectures would provide the basic background, while a significant part of the seminar would consist in the close reading of significant passages and explanation. After clarifying the main arguments of the text discussion would follow.

I build my argument for the effects of teaching philosophy on moral and political development in the Central Asian context firstly on the features of philosophical thought expanding students' frame of mind, and secondly by reference to the content/substance of ethical or political questions. As pointed out by Russell in The Problems of Philosophy, the starting reading of the course, 'the impartiality which, in contemplation, is the unalloyed desire for truth, is the very same quality of mind which, in action, is justice, and in emotion is that universal love which can be given to all, and not only to those who are judged useful or admirable' (2001, p. 93). I investigate to what extent this view has been transmitted to the class through the students' perspective, and through my experience with teaching the course. I first analyze questionnaires from students who took the course between 2015 and 2017 concerning how the course changed their views on ethics and politics (see Appendix B for the questions). Secondly, I overview how the students' answers and classroom experiences relate to the earlier considerations by Kohlberg and Nucci.

The interviewees were students from Kyrgyzstan, Afghanistan, Mongolia, and Tajikistan majoring in Computer Science, Economics, Environmental Management, and Political Science. Concerning earlier background in philosophy, none of the students mentioned secondary school, while most students referred to philosophical texts part of other university courses (first year writing). In addition, some students mentioned informal sources (videos and podcasts, relevant fiction works), and one student mentioned independently reading philosophy.

On the first question, regarding a change in views on ethical problems, most students said that the course changed the way they think about ethics. The answers fit into the following categories:

a) A change in both reasoning and beliefs through engagement with the philosophical literature. For instance, a student connects ethical beliefs to action, and shows a new understanding of moral concepts: 'studying philosophy taught me (...) better beliefs. Once I have a better belief I will be able to have [a] good behavior. (...) Before, virtue 
and happiness had different meanings for me, however, now virtue is the main element of ethical thinking for me. (...) I understood that happiness is my main purpose of life and I should be moral in order to be happy'.

b) Not necessarily a change in beliefs, but a change in reasoning processes. For instance, a student mentions the ability of asking questions: 'this class taught me [about] subjects that are (...) normal in our day-to-day life and we do not question them (...) [and] gave me the opportunity to deeply think about these topics and learn the points of view of different philosophers'. Likewise, another student holds that 'the course did not change my views but it broadened my ideas. After the course, I was well informed about ethical problems and about different approaches'. Another student reports 'better understanding of (...) virtue, happiness, good or evil than before. For example what is justice, and that human beings are gifted with an ability of differentiating (...) good and evil or [a] just person and [an] unjust person (...) why certain things are correct and incorrect'.

C) No significant change in beliefs or reasoning, but exposure to different views. For instance, 'I found Aristotle's idea of happiness that (...) virtuous people must be happy (all the time) to be interesting. But my view that happiness is temporary, fleeting moments did not change. Also, through the course I came to see how virtue was an important topic in many of the early philosophy works.' Another student reported that his/her 'perception of happiness changed to little extent'.

The answers to the second question, regarding a change in political views, can be classified along the same lines, although fewer students reported change. A student giving a negative answer mentioned already having 'consolidated views on politics and its connection to ethics and society'. The the positive answers include the following:

a) While the views are not clearly stated, the students connect the concepts and arguments in the texts to political problems. For instance, a student mentions agreement with Plato’s views on who the rulers should be while specifying: 'to be precise, I do not mean [a] philosopher exactly, but a person who tends toward morality and righteousness'. Another student mentions questioning the political actors: 'this course taught me to look into the behaviors of the rulers and citizens of the state in [a] different way. From (...) Plato's Republic and Aristotle's Nichomachean Ethics I have learned about choosing a good leader [on] whom the fates of the citizens depend'. Another student connects questioning to other philosophical disciplines: 'by questioning (...) what the law is or what form should [a] government take to protect individuals' freedom and rights in order to be (...) ethical (...) I could learn all this by analyzing (...) through metaphysics and epistemology 
perspectives. For instance, when I studied about Aristotle, in his politics he stated that a political community should bring virtuous lives for citizens’.

b) The students mainly report a change in reasoning. For example: '[the course] gave me the chance to look at different points of view regarding who deserves to be a ruler and who does not. Plato, for instance, argued that only philosophers should rule because they have the knowledge to distinguish the good and the bad. Philosophy, I believe, plays a vital role in shaping (...) political views'. Another student points out becoming aware of the connection between moral concepts and politics.

Regarding change in other ways of thinking or skills, one student gave a negative answer mentioning difficulties concerning the length of the course and the readings not being in their native language. This claim may refer to difficulties with English, or to an underlying assumption that studying a subject in the students' native language would be more effective; both interpretations would require further investigation. The majority of the answers fall in the following categories:

a) Change in reasoning in relation to various domains and concepts: 'think critically, do my research, contemplate on [philosophical] topics, and think broadly', 'change in terms of logical reasoning due to being exposed to fallacious arguments', 'philosophy gives (...) new ways of thinking about life. Especially studying about reasoning and morality then trying to practice it (...) in life [is] interesting and new. Philosophy doesn't tell me what to believe, however it helps me to think [in a] more reasonable [way]', 'this course has enhanced my knowledge, it helped me (...) think on the issues from different sides, such as looking [at] the morality and ethics of the certain actions. (...) For instance, why people had a revolution in Kyrgyzstan?', 'The course taught me to think widely and that there might be other possible ways to think about (...) ethical problems'.

b) Interest in specific topics from the course material: arguments about the nature of universals, the ontological argument for God's existence, Hume’s criticism of the notion of necessary connection.

Overall, the answers can be grouped around three main categories through which the introductory course in philosophy influenced students’ ethical and political thought:

i. Improvement of reasoning skills. This is shown through answers mentioning reasoning about topics in moral philosophy, but also overall argumentation skills.

ii. Encouraging students to think from a perspective beyond their own. This holds especially for the students who did not report a significant change in their views, but have reported awareness of philosophical problems and views different from their own. 
iii. Instilling the capacity to distinguish between different values, and views on morality. This only works for the students that referred to particular views, such as Aristotle on virtue, or the rulers from Plato's Republic. Further improvement is shown by students who can connect these views to other questions they are interested in - the history of their own country, their views on society.

Reading these results alongside the recommendations by Kohlberg and Nucci, indicates autonomous moral reasoning - reference to universal principles of governing the society, and also pluralism - students arrive at their own views, but are aware of different positions and arguments. Regarding the challenges of the Central Asian context, the contribution to general reasoning skills may compensate for the shortcomings of secondary school, while also providing undergraduates with deeper understanding of moral and political topics. The capacity to distinguish between philosophers and views also answers the worry above, with respect to whether the use of moral and political concepts necessarily marks an understanding of these issues. While there are still significant shortcomings, particularly in relation to language (as mentioned above, it may be proficiency in English, wider difficulties with philosophical concepts, or the absence of resources in the students' native languages), the answers show that students who were successful in the philosophy course can reflect on specific moral and political topics, as well as on their general reasoning and argumentation skills.

Observations over four semesters of teaching the course are in line with the perspective above concerning the general issues of education in Central Asia and moral reasoning. Regarding challenges, the limited exposure to academic texts alongside the insufficient training in reading, as well as the absence of theoretical foundations for moral and social values were visible in the classroom. These issues extend beyond philosophy: they were noted in other courses in the humanities. Students' difficulties with reading particularly affected the seminars. For example, when asked to find Plato's view on what education is in The Republic, Book VII, many students mistook what education was said not to be for a definition of education. This shows that the issue does not appear to be insufficient knowledge of English, or philosophical vocabulary, but the overall practice of reading a text and gaining awareness of the different perspectives and voices presented. Likewise, students had difficulty with Nietzsche's writing, particularly in separating the author's arguments from the views he criticized. I have addressed these problems through close reading exercises on important passages and argument reconstruction. From the class experience, and from the student feedback, I have noted that the close reading exercises worked particularly well when bringing printed copies of the chapters which students could annotate. These developments show that enhancing reading skills in 
particular, and more generally humanities education, in the context of Central Asia requires materials to aid the pedagogical process: sufficient library copies of the core texts, course readers, or a satisfactory printing quota for students.

Concerning students' interpretation abilities, the lack of an integrating theoretical perspective noted above was clearly visible. When encouraged to integrate particular questions, especially of moral and political nature, under a broader perspective, in the absence of exposure to philosophical, historical, or social science scholarship, many students would refer to popular self-help literature. This appears to be part of a more general pattern in Post-Soviet Central Asia, previously pointed out in sociological research on contemporary Russia: the increasing interest in popular self-help literature as a source of meaning and value. As noted by Salmenniemi, 'the structural distrust characteristic of Russian society, coupled with a widespread sense of political powerlessness (...) encourages people to work on what they feel can be influenced and transformed: their own feelings, thoughts, and behavior' (2012, p. 68). In these circumstances, one function attributed to self-help literature is 'searching for new blueprints for ethical work on the self after a profound transformation of the ideological field' (Salmenniemi 2016, p. 1). In higher education, this tendency leads to students viewing the purpose of the humanities as selfhelp. I have witnessed repeated instances of students reading Plato as a guide to 'thinking outside the box'. This was not limited to philosophy; in another course students went as far as reading Kafka's 'A Report to an Academy' as a guide to freedom and self-fulfillment. I take these shortcomings to be marks of the social changes and their impact on the education system in Central Asia, rather than simply issues with language or vocabulary. Unlike training reading, providing students with a background in the history of philosophy and with a sense of what philosophical texts do is more difficult. For this purpose I found the lecture format useful: sketching a timeline of events, thinkers, and works written, and coming back to it throughout the term and placing the new readings and thinkers in context. Once again, the benefits of this approach are limited given the absence of foundational courses in culture and history, which could compensate for the deficiencies of secondary education.

The challenges noted in class match the general issues with education in Central Asia, as well as with wider social phenomena in post-Soviet states. Regarding how studying philosophy can help address some of these issues, I refer to student contributions to class discussion, and their evaluations. Concerning expanding students' understanding of moral and political issues, introducing Plato's or Aristotle’s ideas was followed by questions where students were to find examples beyond the text. Students showed they could extend the general principles to more familiar contexts: when considering examples of historical or literary characters to illustrate 
Aristotle's views on happiness, virtue and dealing with misfortune, students brought about the case of a notable figure of Kyrgyz history, Kurmanjan Datka, as an example of how virtue affects coping with loss. Also during class debates where different students defended or criticized Aristotle's views, students showed awareness of the distinction between moral and intellectual virtue, and used it to delimit cases where Aristotle's view on moral virtue is not applicable. In doing so, they referred to particular pages and passages in support of this distinction. This shows that engagement with philosophical texts, especially when motivated by class discussion and argument can help overcome the insufficient exposure to close reading practices. Other class discussions showed students' capacity of sustaining more abstract patterns of thought: in a discussion of Plato's epistemology, students showed awareness of the connection to Plato's metaphysics and theory of the soul, and viewed them as indispensable pieces in understanding Plato's concept of knowledge. Considering the implications of a philosopher's worldview can help students understand more abstract principles (Kohlberg's autonomous stage of moral reasoning), and to go beyond their experience or perspective (Nucci's domain approach). Given its complexity, success on this task was not a common occurrence, and in my view, it was rendered possible by previous exposure to other texts by Plato in other courses, which they could link to the Introduction to Philosophy seminar on Plato. These developments could be further encouraged by a curriculum where foundational liberal arts courses would be planned to reach unifying themes and perspectives.

Regarding student feedback, as it is difficult to address all of the issues above within a single course, the development of moral and political thought in students may be below what a philosophy course can generally offer. Nevertheless, in addition to the student answers above, when asked what they learned from the course, through mid-term and end of the semester feedback forms, many students' answers reflected a preoccupation for the issues discussed above. Thus, students reported an improvement in their language and reading skills, but also the awareness that they have become more educated through knowledge of philosophical views and concepts; improvement of general reasoning skills was also noted. While the teaching evaluations did not directly address moral and political education, they show that a philosophy course can provide students with the reasoning tools as well as the background knowledge to build a deeper understanding of moral and political issues. This would enable deeper reflection on readings addressing moral and political questions, and employment of this skill set to reflect on related texts in their further education.

\section{Conclusion}


The Central Asian setting raises several challenges: insufficient training of reasoning and reading in secondary school, the absence of a theoretical framework for education and/or specific disciplines after the demise of Soviet ideology, no data and measurements on the overall educational system, institutional issues with the universities, and material limitations.

The effects this issues yield on students' moral and political reasoning can be partially ameliorated by an introductory course in philosophy. Even when the objectives do not directly target moral education, as reported by the students who were successful in the philosophy course, reading and discussing relevant texts encourage further reflection on the topic and broaden their perspective. Observations from the classroom corroborate this, by stressing the challenges and in sketching out methods or curricular adjustments to help students overcome these issues, thus gaining a better understanding of moral and political values. In addition to encouraging an appreciation of scholarship, philosophy provides students with the tools to make sense of moral and social issues (asking questions about moral or political concepts, explaining known facts through political or moral concepts, awareness of perspectives different from their own).

These are essential insofar as moral and political values are desiderata for emerging societies, and their importance is further emphasized by the present neglect of theoretical subjects and the search for meaning in the aftermath of abrupt social change. Furthermore, through using philosophy as an example of scholarship, and by acquaintance with broadly theoretical investigations, students can gain a fresh perspective on the social sciences they study, and raise deeper questions of moral or political importance.

\section{References}

Buckland, P. (2006) Post-conflict education: Time for a reality check. Forced Migration Review, 26, pp.7-8.

DeYoung, A. J. (2006) On the Demise of the “Action Plan” for Kyrgyz Education Reform, in S.P. Heyneman \& A.J. DeYoung (Eds.) (2006) The challenges of education in Central Asia. IAP, pp. 199-225.

DeYoung, A.J. (2013) Redefining Students and Universities in Kyrgyz Republic, in Akçalı, P. and Engin-Demir, C. eds., 2013. Politics, Identity and Education in Central Asia: Post-Soviet Kyrgyzstan (Vol. 3). Routledge, pp. 158-190.

Dewey, J. (1964) What Psychology Can Do for the Teacher, in R. Archambault (ed.), John Dewey on Education: Selected Writings. New York: Random House. 
Graham, L., (1972) Science, Philosophy, and Human Behavior in the Soviet Union, New York: Columbia University Press.

Jarrar, A. (2013). Moral Values Education in Terms of Graduate University Students' Perspectives: A Jordanian Sample. International Education Studies, 6(2), 136-147.

Kant, I., \& Schneewind, J. B. (2002). Groundwork for the Metaphysics of Morals. Yale University Press.

Khamidov, A. (2016) 'Kyrgyzstan: Medieval Philosopher Reclaimed as National Hero' Eurasianet, URL: https://eurasianet.org/s/kyrgyzstan-medieval-philosopher-reclaimed-asnational-hero (last accessed August 11, 2018).

Kohlberg, L. (1975) The cognitive-developmental approach to moral education. The Phi Delta Kappan, 56(10), pp. 670-677.

McNeel, S.P. (1994) College teaching and student moral development. Moral development in the professions: Psychology and applied ethics, 27, p.49.

Merrill, M. C. (2011). Kasha and quality in Kyrgyzstan: Donors, diversity, and dis-integration in higher education. European Education, 43(4), 5-25.

Nucci, L. (2005) Education for Moral Development, in M. Killen and J. Smetana (eds.), Handbook of moral development. Psychology Press, pp. 657-683.

Nyozov, S. (2006) The Effects of the Collapse of the USSR on Teacher's Lives and Work in Tajikistan, in S.P. Heyneman \& A.J. DeYoung (Eds.). (2006). The challenges of education in Central Asia. IAP, pp. 37-75.

Piaget, J. (1932) The moral judgment of the child. New York: Free Press.

Rahmetov, A. (2009) Scary statistics: The state of schools in Kyrgyzstan. Central AsiaCaucasus Institute Analyst.

Reeves, M. (2005). Of Credits, Kontrakty and Critical Thinking: Encountering 'market reforms' in Kyrgyzstani higher education. European Educational Research Journal, 4(1), 5-21.

Reeves, M. (2006) Cultivating “Citizens of A New Type”, in S.P. Heyneman \& A.J. DeYoung (Eds.). (2006). The challenges of education in Central Asia. IAP, pp. 365-387.

Russell, B. (2001) The problems of philosophy. OUP Oxford.

Salmenniemi, S. (2012) Post-soviet khoziain: class, self and morality in Russian self-help literature. Rethinking class in Russia, pp. 67-84.

Salmenniemi, S. (2016) 'We can't live without beliefs': Self and society in therapeutic engagements. The Sociological Review, pp. 611-627.

Samady, S.R. (2001) Education and Afghan society in the twentieth century. Afghan Digital Libraries. 
Shamatov, D. (2014) Education Quality in Kyrgyzstan and the Programme for International Student Assessment (Pisa). In Qualities of Education in a Globalised World. SensePublishers, pp. 43-62.

Siegel, H. (ed.) (2009) The Oxford Handbook of Philosophy of Education, Oxford: Oxford University Press. 


\title{
APPENDIX A
}

\section{Syllabus: Introduction to Philosophy}

\author{
Excerpts
}

\section{Course description}

This course is meant to provide the students with an introduction to philosophy from a problem/ debate-oriented approach. The course includes a weekly lecture for all the students and two seminars with smaller student groups. Attendance to both courses and seminars is required. Students are expected to read all of the required material, turn in all the assignments on time, and take the final exam.

\section{Course rationale}

This course is designed to provide students with an analytical frame of mind and critical tools for assessing arguments; students are also to present their own arguments through discussion and written work. It is also meant to be an introduction to the further work that students will do in the humanities or social sciences. Along with providing the tool kit of argumentation, analysis and interpretation, useful in studying philosophy, but also in other academic fields, this introductory course may also help the students understand the place of philosophical problems among the other academic subjects they will be studying.

\section{Goals}

- Students are expected to familiarize with classic debates and arguments presented in the core readings: what philosophy is, what the major questions and approaches concerning the topics discussed in class are.

- Students should be able to use the concepts discussed in class in their research questions concerning the disciplines in which they specialize.

- Students should acquire the skills necessary for understanding and assessing texts belonging to the philosophical and humanities literature.

\section{Weekly Readings and Themes}

1. What is philosophy? 
B. Russell, The Problems of Philosophy, Ch. 15, 9.

\section{Plato's theory of the forms}

Plato, The Republic, 505 b-521 c.

3. Ethics and happiness

Aristotle, Nicomachean Ethics, Book 1.

4. The ontological argument for God's existence

Anselm, Proslogion. Ch.1-4;

D. Haight \& M. Haight, 'An ontological argument for the devil', The Monist.

5. Rationalism

R. Descartes,Meditations on the First Philosophy, Ch. 1-2.

6. Empiricism

D. Hume, An Enquiry Concerning Human Understanding, section 7.

7. The limits of knowledge

I. Kant, Prolegomena to Any Future Metaphysics, Introduction, Preamble on the peculiarities of all metaphysical cognition.

8. Against the idea of a 'true world'

F. Nietzsche, The Twilight of the Idols, 'Reason in philosophy', 'Morality as anti-nature'.

9. Philosophy and science: the problem of method

K. Popper, Conjectures and Refutations, Ch. 1.

10. What is language?

L. Wittgenstein, The Blue Book, pp. 1-10. 


\section{APPENDIX B}

\section{Questionnaire form}

\section{Personal information}

Note: This section is for statistical purposes only, the personal information will not be disclosed in the study.

Name:

Country of origin:

Major/Department:

\section{Background question}

Have you studied philosophy previously? If so, specify if it was in a secondary school, or a university.

\section{Questionnaire}

1. Did the 'Introduction to Philosophy' course change your views on ethical problems (such as virtue, happiness, good and evil)? If so, how?

2. Has the 'Introduction to Philosophy' course changed your views on politics (e.g., on rulers, connection to ethics, society)? If so, how?

3. Has the 'Introduction to Philosophy' course changed your thinking in other ways? If so, how? 